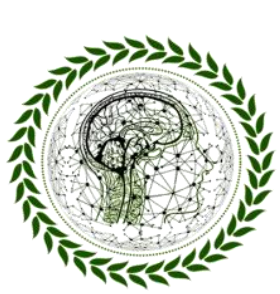

PhD Seientific Review

ISSN 2676 - 044

Submetido em: 15/01/2022 | Aceito em: 20/01/2022 | Publicado em: 24/01/2022 | Artigo

\title{
DO DIREITO À EDUCAÇÃO DAS PESSOAS EM SITUAÇÃO PRIVAÇÃO DE LIBERDADE NO BRASIL
}

Fernando Lannes Villela ${ }^{1}$

\begin{abstract}
Resumo: A Constituição Federal de 1988 garante que a educação é um direito de todos os cidadãos brasileiros e estrangeiros residentes. Por tal motivo, a legislação infraconstitucional, bem como os tratados internacionais que o Brasil é signatário, garantem as pessoas em situação de liberdade o direito à educação enquanto estas encontrarem-se sob a tutela do estado. Contudo, o pleno acesso à educação no âmbito do sistema prisional ainda está longe de ser uma realidade em muitos presídios brasileiros, do mesmo modo com que a adesão dos apenados e presos provisórios às atividades educacionais ainda é muito tímida, se comparada ao grande contingente de pessoas privadas de liberdade em nosso país. Desse modo, tendo em vista que a educação é um instrumento indispensável para viabilização da ressocialização das pessoas privadas de liberdade, o presente artigo apresenta considerações e dados estatísticos acerca do direito à educação das pessoas em situação privação de liberdade no âmbito do sistema prisional brasileiro.
\end{abstract}

Palavras-chave: Direito à educação. Educação no sistema prisional. Ressocialização.

\section{THE RIGHT TO EDUCATION OF PEOPLE IN SITUATION DEPRIVATION OF FREEDOM IN BRAZIL}

\begin{abstract}
The Federal Constitution of 1988 guarantees that education is a right of all Brazilian citizens and resident foreigners. For this reason, the infra-constitutional legislation, as well as the international treaties that Brazil is a signatory, guarantee people in a situation of freedom the right to education while they are under the tutelage of the state. However, full access to education within the prison system is still far from being a reality in many Brazilian prisons, in the same way that the adhesion of inmates and provisional prisoners to educational activities is still very timid, compared to the large contingent of people deprived of liberty in our country. Thus, considering that education is an indispensable instrument for enabling the re-socialization of people deprived of liberty, this article
\end{abstract}

${ }^{1}$ Bacharel em Direito pela Universidade Estácio de Sá - UniEstácio.

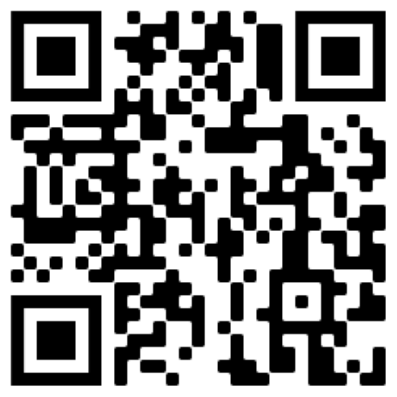

http://www.revistaphd.periodikos.com.br DOI: http://dx.doi.org/10.53497/phdsr2n1-004

V. 02, No 01, janeiro de 2022

Todos os direitos reservados $($ ) 


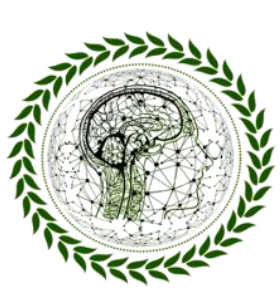

PhD Seientific Review

ISSN 2676 - (144

presents considerations and statistical data about the right to education of people deprived of liberty within the scope of the Brazilian prison system.

Keywords: Right to education; Education in the prison system; Resocialization.

\section{INTRODUÇÃO}

A educação é um direito de todos, incluindo as pessoas em privadas de liberdade. Todavia, o pleno acesso ao direito à educação por essa parcela da população ainda não é uma realidade no âmbito do sistema prisional brasileiro. Em muitos estados e unidades prisionais brasileiras não há oferta de ensino ou disponibilidade de vagas suficientes, de modo a abarcar o grande número de pessoas privadas de liberdade que abrigam em suas instalações. Por tal motivo, o presente artigo apresentará considerações e dados estatísticos acerca do direito à educação das pessoas em situação privação de liberdade no âmbito do sistema prisional brasileiro.

É importante destacar que a população prisional é composta em sua grande maioria por homens e mulheres pobres e de baixa escolaridade. Nesse sentido, a educação é uma ferramenta indispensável para fomentar o desenvolvimento pessoal, viabilizar a qualificação e o crescimento profissional, bem como para criar condições que permitam a transformação social e diminuição das desigualdades e a violência, ou seja, a educação é fundamental para criar bases que estimulem e auxiliem na ressocialização desses indivíduos.

Desse modo, o presente artigo busca analisar o direito à educação prisional na legislação brasileira e compreender se esse direito é exercido e em caso positivo, de que forma e em que condições é exercido, bem como analisar a relação da educação

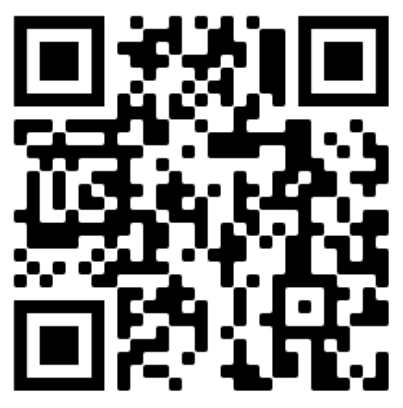

http://www.revistaphd.periodikos.com.br DOI: http://dx.doi.org/10.53497/phdsr2n1-004

V. 02, No 01, janeiro de 2022 Todos os direitos reservados $($ ) 


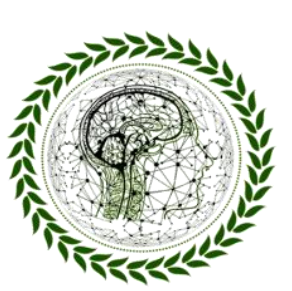

PhD Seientific Review

ISSN 2676 - 0444

com o processo de ressocialização desses indivíduos em privação de liberdade.

Desse modo, iniciaremos a pesquisa com um breve histórico sobre as formas de punir, com ênfase no deslocamento da concepção da pena como um castigo até a visão moderna de que a pena deve possuir uma função ressocializadora e não apenas retributiva. Em seguida, apresentaremos considerações e dados estatísticos acerca do Direito e acesso à educação das pessoas privadas de liberdade no Brasil.

Para realização desses objetivos a pesquisa utiliza o método de revisão bibliográfica, com análise de dados fornecidos por órgãos federais de Gestão Prisional e Justiça e amparada na legislação brasileira e nos estudos de BARATTA (2007), BRANDÃO (2017), BITENCOURT (2011) FOUCAULT (1979 e 2008), GRACIANO (2008), ROIG (2021), RODRIGUES (1982), ROXIN (1986) e SILVA (2013).

\section{BREVE HISTÓRICO SOBRE AS FORMAS DE PUNIR: DOS CASTIGOS FÍSICOS À FUNÇÃO RESSOCIALIZADORA DA PENA}

Ao longo da história a sociedade adotou diversas formas de punir os comportamentos considerados desviantes. Durante muitos séculos prevaleceram os castigos físicos e execuções públicas. Ou seja, a pena centrava-se na punição corporal do indivíduo.

O filósofo Michel Foucault destaca que a partir do fim do século XVIII, houve uma mudança de paradigma no que se refere a forma de punir. Baseada nos ideias iluministas passou-se a adotar a noção de que as penas cruéis e os suplícios públicos deveriam ser substituídos ocorrendo, portanto, um deslocamento na forma de punir “é preciso que a justiça criminal puna em vez de se vingar" (FOCAULT, 2008, p.63).

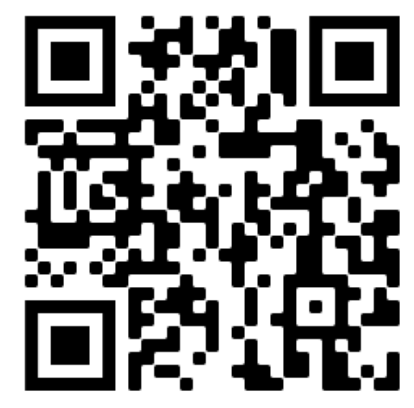

http://www.revistaphd.periodikos.com.br DOI: http://dx.doi.org/10.53497/phdsr2n1-004

V. 02, $\mathrm{N}^{\mathrm{o}}$ 01, janeiro de 2022 Todos os direitos reservados (C) 


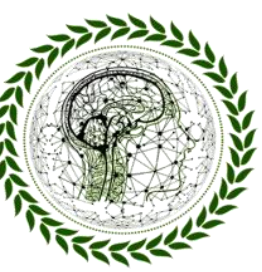

PhD Scientific Review

ISSN 2676 - 0444

Habitualmente se acredita que a prisão era uma espécie de depósitos de criminosos, depósitos cujos inconvenientes se teriam constatado por seu funcionamento, de tal forma que se teria dito ser necessário reformar as prisões, fazer delas um instrumento de transformação dos indivíduos. (FOUCAULT, 1979, p.131).

Nesse sentido, Bitencourt afirma que as prisões não deixaram de existir, em razão de que apesar de ser uma solução pungente, sua existência é indispensável. Desse modo, ao invés de extintas as prisões e as formas de punir foram se transformando nos compasso das mudanças sociais, econômicas e ideológicas da sociedade.

A prisão é uma exigência amarga, mas imprescindível. A história da prisão não é a de sua progressiva abolição, mas a de sua reforma. A prisão é concebida modernamente como um mal necessário, sem esquecer que as mesmas guardas em sua essência contradições insolúveis (BITENCOURT, 2011, p. 505).

Uma dessas mudanças que nos interessa se refere às funções da pena. Conforme destacado acima, a partir do fim do século XVIII a compreensão da pena como instrumento de obtenção de vingança, foi substituída pela noção de pena como forma de punição do individuo transgressor. Ou seja, a pena irá puni-lo na medida de seu desvio e não castigá-lo como forma de vingança.

Contudo, com o passar dos anos verificou-se que não bastava apenas punir, mas permitir que a permanência no cárcere servisse como forma de recuperação do apenado, de modo que este não viesse a cometer novos crimes e fosse reintegrada a sociedade. Ou seja, a função preventiva da pena, isto é, o medo de ser preso e punido novamente não se mostrava suficiente, por si só, para evitar que aqueles indivíduos voltassem a delinquir. Nessa linha, Leandra Silva afirma:

A busca por alternativas surge no momento em que a pena, baseada

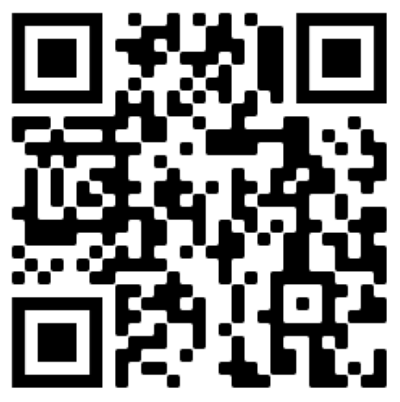

http://www.revistaphd.periodikos.com.br DOI: http://dx.doi.org/10.53497/phdsr2n1-004

V. 02, $\mathrm{N}^{\mathrm{o}}$ 01, janeiro de 2022 Todos os direitos reservados ( 


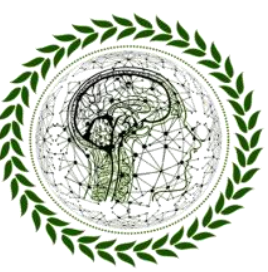

PhD Scientific Review

ISSN 2676 - 0444

unicamente na privação da liberdade, não vinha contribuindo com o seu papel de reinserir o apenado à sociedade devido aos altos índices de violência, reincidência criminal e a não adaptação do egresso à vida em sociedade. Diversos mecanismos de defesa dos direitos humanos engendraram uma luta em favor da humanização no cumprimento das penas e do fim da violação de direitos, culminando com a criação de diversos dispositivos legais de proteção aos direitos da pessoa humana (SILVA, 2013, p. 179).

Nesse sentido, a pena adquire uma nova função, a chamada função ressocializadora, que pressupõe que o período que o individuo permanece no sistema prisional deve ser aproveitado para reintegração dos indivíduos privados de liberdade, de modo que ao retornarem ao convívio social, não permaneçam na criminalidade. Nesse sentido afirma o jurista alemão Claus Roxin:

[...] servindo a pena exclusivamente fins racionais e devendo possibilitar a vida humana em comum e sem perigos, a execução da pena apenas se justifica se prosseguir esta meta na medida do possível, isto é, tendo como conteúdo a reintegração do delinquente na comunidade. Assim, apenas se tem em conta uma execução ressocializadora. O fato da ideia de educação social através da execução da pena ser de imediato tão convincente, deve-se a que nela coincidem prévia e amplamente os direitos e deveres da coletividade e do particular, enquanto na cominação e aplicação da pena eles apenas se podem harmonizar através de um complicado sistema de recíprocas limitações. (CLAUS ROXIN, 1986, p. 40)

Desse modo, sob esse ponto de vista, o comportamento criminoso é concebido também como o resultado de um prejuízo na socialização do individuo que o cometeu, sendo, portanto, necessário viabilizar sua reinserção social e “integrar o indivíduo no mundo dos seus concidadãos, sobretudo nas coletividades sociais básicas como, por exemplo, a família, a escola ou o trabalho, proporcionando o auxílio necessário que o faça ultrapassar a situação de defasamento social em que se encontra" (RODRIGUES, 1982, p. 29).

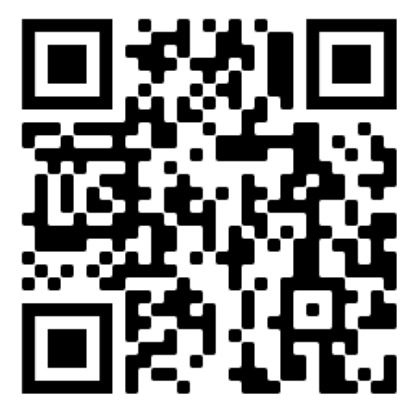

http://www.revistaphd.periodikos.com.br DOI: http://dx.doi.org/10.53497/phdsr2n1-004

V. 02, $\mathrm{N}^{\mathrm{o}}$ 01, janeiro de 2022

Todos os direitos reservados ( 


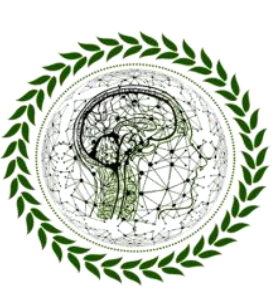

PhD Seientific Review

ISSN 2676 - 1444

Ocorre que apesar dessas mudanças nas formas de punição, a prisão ainda está longe de ser um lugar apto para reintegração do apenado “desde 1820 se constata que a prisão, longe de transformar os criminosos em gente honesta, serve apenas para fabricar novos criminosos ou para afundá-los ainda mais na criminalidade" (FOUCAULT, 1979, p.132).

No mesmo sentido, Bitencourt (2011, p.167) argumenta ser impossível ansiar que a privação de liberdade reintegre por meio da exclusão e do isolamento. $O$ mesmo autor afirma que o desinteresse governamental e a falta de investimentos atingem os sistemas penitenciários do mundo todo e não apenas o Brasil “a manifesta deficiência das condições penitenciárias existente na maior parte do mundo, faz pensar que a prisão se encontra em crise, como resultado da deficiente atenção que os governantes têm dispensado ao problema" (BITENCOURT, 2011, p.167).

Na mesma linha de pensamento, o sociólogo e jurista italiano Alessandro Baratta afirma que há a necessidade de um maior diálogo entre as pessoas em privação da liberdade e a sociedade, bem como um intercâmbio entre a sociedade e a prisão, de modo a viabilizar a reintegração do apenado quando este retornar ao convívio social.

\begin{abstract}
Ressaltamos a necessidade da opção pela abertura da prisão à sociedade e, reciprocamente, da sociedade à prisão. Um dos elementos mais negativos das instituições carcerária, de fato, é o isolamento do microcosmo prisional do macrocosmo social, simbolizado pelos muros e grades. Até que não sejam derrubados, pelo menos simbolicamente, as chances de "ressocialização" do sentenciado continuarão diminutas. Não se pode segregar pessoas e, ao mesmo tempo, pretender a sua reintegração (BARATTA, 2007, p. 03).
\end{abstract}

Desse modo, é preciso reconhecer a necessidade de transposição desses obstáculos, de modo a construir alternativas ao cumprimento de uma pena que não 


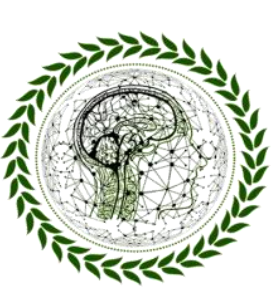

PhD Seientific Review

ISSN 2676 - 1444

forneça aos indivíduos condições mínimas de transformação das condições que o levaram a delinquir. É sabido que a maior parte das pessoas privadas de liberdade no Brasil é formada por homens e mulheres, negros e de baixa escolaridade, conforma apontam os números do Levantamento Nacional de Informações Penitenciárias, publicado em dezembro de 2020 (INFOPEN.2020).

\begin{abstract}
Se verificarmos a população carcerária, sua composição demográfica, veremos que a marginalização é, para a maior parte dos presos, oriunda de um processo secundário de marginalização que intervém em um processo primário. É fato comprovado que a maior parte dos presos procedem de grupos sociais já marginalizados, excluídos da sociedade ativa por causa dos mecanismos de mercado que regulam o mundo do trabalho. A reintegração na sociedade do sentenciado significa, portanto, antes de tudo, corrigir as condições de exclusão social, desses setores, para que conduzi-los a uma vida pós-penitenciária não signifique, simplesmente, como quase sempre acontece, o regresso à reincidência criminal, ou o à marginalização secundária e, a partir daí, uma vez mais, volta à prisão. (BARATTA, 2007, p. 03).
\end{abstract}

Desse modo, um dos obstáculos para que a reintegração social das pessoas privadas de liberdade é a falta de oportunidades que lhes viabilize uma vida digna e lícita, afastada da criminalidade e da marginalização social. Nesse sentido, a educação é um dos elementos que podem auxiliar a evitar que o ciclo de exclusão, violência e marginalização desses indivíduos se perpetue, levando a reincidência, ou até mesmo a morte.

Importante ressaltar que não é qualquer educação que será capaz de alterar esse estado de coisas, mas uma educação que dialogue com o mundo e com isso promova aprendizagens significativas e emancipadoras, de modo a fazer com que o aluno seja capaz de compreender e intervir na realidade social, transformando- a e transformando sua história.

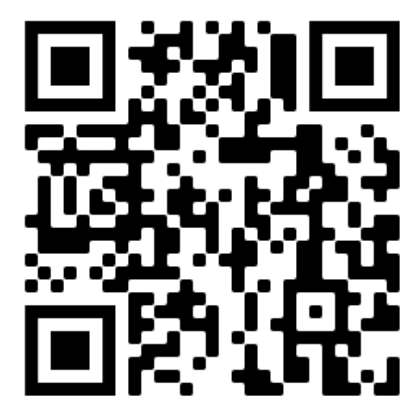

http://www.revistaphd.periodikos.com.br DOI: http://dx.doi.org/10.53497/phdsr2n1-004

V. 02, $\mathrm{N}^{\mathrm{o}}$ 01, janeiro de 2022

Todos os direitos reservados $($ ) 


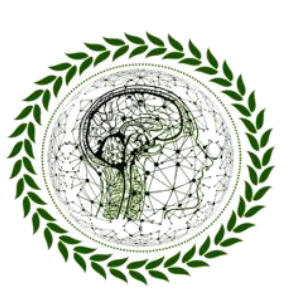

PhD Seientific Review

ISSN 2676 - 1444

No capítulo a seguir teceremos alguns comentários acerca do direito à educação das pessoas privadas de liberdade no Brasil e analisaremos alguns dados a respeito do acesso à da educação no sistema prisional brasileiro com base nos últimos Levantamentos Nacionais de Informações Penitenciárias publicados pelo Departamento Penitenciário Nacional.

\section{DIREITO E ACESSO À EDUCAÇÃO DAS PESSOAS PRIVADAS DE LIBERDADE NO BRASIL}

A Lei Federal n. 7.210 de 11 de Julho de 1984, conhecida como Lei de Execução Penal prevê em seu artigo 10 que a assistência ao preso é dever do Estado e objetiva prevenir o crime e orientar o retorno deste à convivência em sociedade. $\mathrm{O}$ mencionado artigo detalha que tal assistência deverá ser material, jurídica, educacional, social, religiosa e de saúde.

Além de direito da pessoa em privação de liberdade, a educação é um direito social consagrado na Constituição Federal de 1988 e juntamente com o trabalho, a cultura, o lazer e o esporte é um instrumento de fundamental para ressocialização das pessoas que se encontram em privação de liberdade e consequentemente, é ferramenta de diminuição da criminalidade e da reincidência.

Desse modo, se a pessoa em privação de liberdade tem acesso à educação, a saída do cárcere e o retorno dela ao convívio social poderá ser ressignificado, uma vez que a educação viabiliza novas formas de percepção o mundo e a realidade social. Nesse sentido, afirma o professor Rodrigo Roig: “De fato, a educação deve ser estimulada com o objetivo de promover a aquisição, por parte dos internos, das

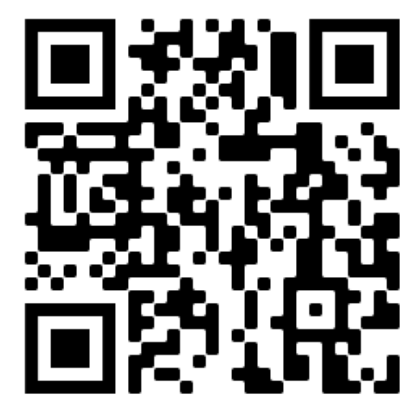

http://www.revistaphd.periodikos.com.br DOI: http://dx.doi.org/10.53497/phdsr2n1-004 V. 02, No 01, janeiro de 2022 Todos os direitos reservados $($ ) 


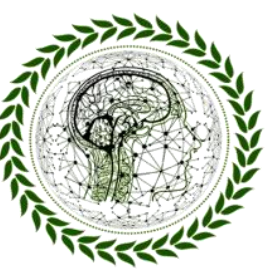

PhD Scientific Review

ISSN 2676 - 0444

ferramentas necessárias que lhes permitam diminuir seu nível de vulnerabilidade, evitando a constante prisionização" (ROIG, 2021, p. 162).

Ao dissertar sobre o que é a educação, Brandão (2017) destaca que na sociedade “[...] Não há uma forma única nem um único modelo de educação; a escola não é o único lugar onde ela acontece e talvez nem seja o melhor; o ensino escolar não é a sua única prática e o professor profissional não é o seu único praticante" (BRANDÃO, 2017, p. 9). Para ele, não é correto afirmar que existe educação no singular, mas sim educações, já que a educação pode ser encontrada em diversos lugares em diferentes formatos.

\begin{abstract}
Em mundos diversos a educação existe diferente: em pequenas sociedades tribais de povos caçadores, agricultores ou pastores nômades; em sociedades camponesas, em países desenvolvidos e industrializados; em mundos sociais sem classes, de classes, com este ou aquele tipo de conflito entre as suas classes; em tipos de sociedades e culturas sem Estado, com um Estado em formação ou com ele consolidado entre e sobre as pessoas (BRANDÃO, 2017, p. 9).
\end{abstract}

Nesse sentido, o Brandão (2017) acrescenta ainda que historicamente a educação revela sua dimensão difusa.

Da família à comunidade, a educação existe difusa em todos os mundos sociais, entre as incontáveis práticas dos mistérios do aprender; primeiro, sem classes de alunos, sem livros e sem professores especialistas; mais adiante com escolas, salas, professores e métodos pedagógicos (BRANDÃO, 2017, p. 9).

De acordo com citado autor, a educação deve ser compreendida em seu sentido amplo, isso quer dizer que a educação não se restringe apenas ao espaço escolar, ela se relaciona com a existência humana. A educação envolve todos os sujeitos em suas vivências, culturas e práticas sociais. A educação mistura-se com a vida, seja na rua, na escola, na igreja ou na prisão.

http://www.revistaphd.periodikos.com.br DOI: http://dx.doi.org/10.53497/phdsr2n1-004

V. 02, $\mathrm{N}^{\mathrm{o}}$ 01, janeiro de 2022

Todos os direitos reservados $($ ) 


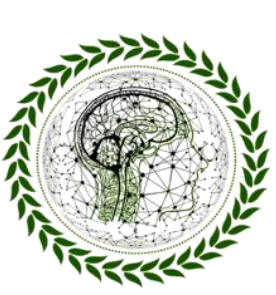

PhD Seientific Review

ISSN 2676 - 1444

Segundo Graciano e Schilling (2008) inciativas educacionais quase não eram observadas na maioria dos presídios brasileiros e as que existiam eram insuficientes até o a data da publicação do artigo, em 2008. De acordo com esses autores, somente em 2005 ocorreu uma iniciativa do Ministério da Educação através da Diretoria de Educação de Jovens e Adultos, da Secretaria de Educação Continuada, Alfabetização e Diversidade (Secad/MEC), em parceria com o Ministério da Justiça e a Secretaria de Direitos Humanos da Presidência da República criou um projeto educativo voltado para a população carcerária brasileira. Nesse sentido, esses mesmo autores pontuam que a falta de iniciativas também é reflexo da invisibilidade da questão nas próprias leis brasileiras. Essa questão pode ser compreendida através da leitura da Lei de Diretrizes e Bases da Educação Brasileira N 9.394, de 1996, sobre a qual, os autores ressaltam que

Do ponto de vista formal e administrativo, não se constitui em modalidade de ensino específica, prevista na Lei de Diretrizes e Bases da Educação (LDB, Lei Federal No 9.394, de 20/10/1996), o que pode levar à interpretação de que se insere na modalidade Educação de Jovens e Adultos, afirmada na Seção V do Capítulo II, intitulado Educação Básica, na mesma lei. (GRACIANO; SCHILLING, 2008, p 111).

De acordo com esses autores a partir de 2000 são observadas também mais pesquisas acadêmicas de mestrado e doutorado relacionadas ao tema, diferentemente de 1970, 1980 e 1990, quando não foram encontradas pesquisas acadêmicas com esse objeto de estudo.

Segundo Roig (2021) o direito à educação sustenta-se nos princípios presentes na Declaração Universal dos Direitos Humanos, especificamente por definir em seu conteúdo que "toda pessoa tem direito à instrução e que a mesma será orientada no sentido do pleno desenvolvimento da personalidade humana e do fortalecimento do 


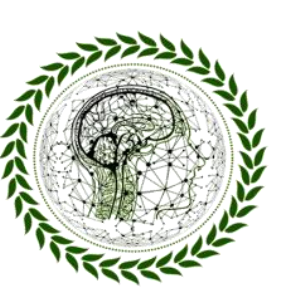

PhD Seientific Review

ISSN 2676 - 1444

respeito pelos direitos humanos e pelas liberdades fundamentais" (ROIG, 2021, p. 161). É importante destacar que esse direito também encontra amparo na Regra 104, n. 1, das novas Regras Mínimas das Nações Unidas para o Tratamento de Presos, que define que ferramentas necessitam ser elaboradas para que os presos possam ter acesso à educação. No Brasil, de acordo com Roig (2021), as inciativas educacionais são baseadas na Constituição Federal. A Constituição Federal de 1988 define no artigo 205 que a educação é um direito de todos e dever do Estado. Além disso, ela define que a educação é a condição para o desenvolvimento das pessoas, para o exercício da cidadania e qualificação para o trabalho. Já o artigo 208 da Constituição Federal estabelece que a assistência educacional aos indivíduos deve englobar também a instrução escolar e a formação profissional da pessoa presa e da internada.

Rodrigo Roig ressalta que de acordo com o Princípio n. 6 dos Princípios Básicos para o Tratamento de Pessoas Presas, da ONU, todas as pessoas em situação de privação de liberdade possuem o direito de participar de atividades culturais e educacionais, de modo a viabilizar o desenvolvimento da personalidade humana de forma plena. O mesmo autor também destaca o art. 26 da Declaração Universal dos Direitos Humanos, o qual preceitua que todas as pessoas têm direito à educação e que a mesma deve se voltar para o pleno desenvolvimento da personalidade humana, bem como pautar-se na proteção e no respeito aos direitos humanos às liberdades fundamentais (ROIG, 2021, p. 257).

Além da Constituição, a Lei n. 13.163/2015, após a inclusão do art. 18-A na Lei de Execução Penal, define que o ensino médio, regular ou supletivo, com formação geral ou educação profissional de nível médio, deve ser disponibilizado nos presídios respeitando o preceito constitucional universalização da educação. Entre outras

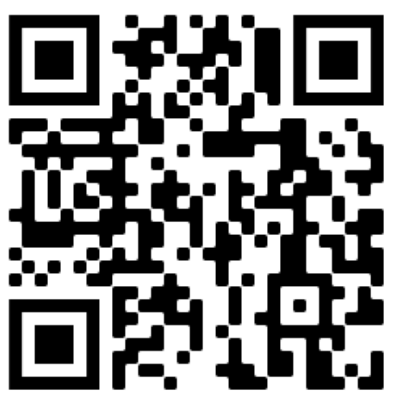

http://www.revistaphd.periodikos.com.br DOI: http://dx.doi.org/10.53497/phdsr2n1-004

V. 02, No 01, janeiro de 2022 Todos os direitos reservados $($ ) 


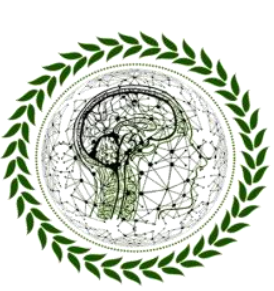

PhD Seientific Review

ISSN 2676 - 1444

definições, essa lei também estabelece que os presídios podem realizar parcerias com entidades particulares ou públicas para oferta de cursos ou escolas. Em conformidade com as condições locais, os estabelecimentos devem contar com uma biblioteca com livros instrutivos, recreativos e didáticos para uso de todos. De acordo com Roig (2021), deve-se ressaltar que o Conselho Nacional de Política Criminal e Penitenciária (CNPCP), através da Resolução n. 03/2009, instituiu as Diretrizes Nacionais para o oferecimento de Educação em presídios. Nesse sentido, destacam-se as seguintes orientações:

[...] as autoridades responsáveis pelos estabelecimentos penais devem propiciar espaços físicos adequados às atividades educacionais (salas de aula, bibliotecas, laboratórios etc.), integrar as práticas educativas às rotinas da unidade prisional e difundir informações incentivando a participação do (a)s preso (a)s e internado (a)s (art. $5^{\circ}$ ); devem ser elaboradas e priorizadas estratégias que possibilitem a continuidade de estudos para os egressos, articulando-as com entidades que atuam no apoio dos mesmos - tais como patronatos, conselhos e fundações de apoio ao egresso e organizações da sociedade civil (art. $7^{\circ}$ ); o trabalho prisional, também entendido como elemento de formação integrado à educação, deve ser ofertado em horário e condições compatíveis com as atividades educacionais (art. $8^{\circ}$ ). (ROIG, 2021, p. 162).

Cumpre ressaltar que de acordo com o artigo 126 da Lei Federal n. 7.210 de 11 de Julho de 1984, a já citada Lei de Execuções Penais, assegura a remissão da pena pelo estudo, sendo que a contagem de tempo para fins de remição em virtude de dedicação do apenado ao estudo é de 1 dia de pena para cada 12 horas de frequência escolar em quaisquer nível de ensino, seja fundamenta, médio, técnico, profissionalizante, superior ou pós graduação, na modalidade presencial ou a distância. O parágrafo 5o do mencionado artigo acrescenta que "o tempo a remir em função das horas de estudo será acrescido de 1/3 (um terço) no caso de conclusão do 


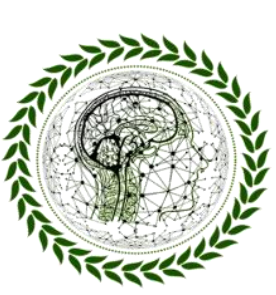

PhD Seientific Review

ISSN 2676 - 1444

ensino fundamental, médio ou superior durante o cumprimento da pena, desde que certificada pelo órgão competente do sistema de educação".

Cumpre ressaltar que a possibilidade de remição pelo estudo é recente e somente foi incluída na Lei Federal n. 7.210 de 11 de Julho de 1984, a Lei de Execuções Penais, em 2011, por meio da Lei Federal no 12.433, de 29 de junho de 2011. Anteriormente a redação do artigo só contemplava a possiblidade de remição pelo trabalho.

Ainda há possibilidade de remição pela leitura, pelo estudo individual e pela dedicação a atividades complementares, as quais vêm sendo muito utilizada em virtude de não necessitar da disponibilidade de vaga no ensino escolar na unidade prisional. A possiblidade e a forma como essas atividades serão exercidas para fins de remição encontram-se reguladas na Resolução no 391 de 10/05/2021 do Conselho Nacional de Justiça, a qual recentemente revogou a Recomendação CNJ no 44/2013. O artigo $2^{\circ}$ da resolução 391, garante as pessoas privadas de liberdade "o reconhecimento do direito à remição de pena por meio de práticas sociais educativas considerará as atividades escolares, as práticas sociais educativas não-escolares e a leitura de obras literárias".

Desse modo, constitui direito subjetivo da pessoa em situação de privação de liberdade o acesso à educação, não se confundindo esse direito com benefício ou regalia de qualquer natureza, na medida em que "tirar da ociosidade uma grande massa da população carcerária, levando-a à sala de aula, não constitui privilégio, mas, sim, uma proposta que responde ao direito de todos à educação e atende aos interesses da própria sociedade" (JULIÃO, 2007, p. 6 apud Santiago, 2021, p.10).

De acordo com o Levantamento Nacional de Informações Previdenciárias de

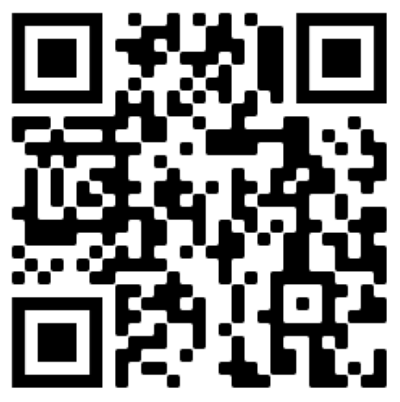

http://www.revistaphd.periodikos.com.br DOI: http://dx.doi.org/10.53497/phdsr2n1-004

V. 02, No 01, janeiro de 2022 Todos os direitos reservados $($ ) 


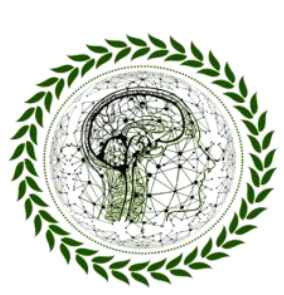

PhD Seientific Review

ISSN 2676 - 0444

2017 período da amostra o Brasil possuía 726.712 pessoas privadas de liberdade, destas 5,85\% eram apenas alfabetizadas, 51,3\% possuíam Ensino Fundamental Incompleto, $13,5 \%$ concluíram o ensino fundamental, 14,9\% possuíam Ensino Médio Incompleto e 13,1\% e 9,65\% concluíram o ensino médio. Com ensino superior incompleto o percentual é ainda menor, 0,97\%, com formação superior completa o percentual é de $0,56 \%$, já a parcela da população prisional com formação acima do superior completo é de 0,04\% (INFOPEN, 2017, p. 34).

No que se refere a população em geral, os dados de escolaridade da população brasileira, fornecidos em 2017 pelo Instituto Brasileiro de Geografia e Estatística IBGE no Relatório da Pesquisa Nacional por Amostra de Domicílios Contínua, citados no Levantamento Nacional de Informações Previdenciárias de 2017, informam que $7,2 \%$ da população eram analfabetos, 33\% possuíam o ensino fundamental incompleto, $8 \%$ possuíam o ensino fundamental completo, 4,4\% possuíam o ensino médio incompleto, $26,8 \%$ concluíram o ensino médio, enquanto que as que possuem ensino superior incompleto representam 3,6\% e as que possuem ensino superior completo 17\% (INFOPEN, 2017, p. 34).

Tais números demonstram que o grau de escolaridade das pessoas em situação de privação de liberdade no Brasil é baixo e não corresponde com a distribuição entre os níveis de escolaridade da população brasileira em geral.

O Levantamento Nacional de Informações Previdenciárias de 2017 também fornece informações relativas ao acesso das pessoas privadas de liberdade à educação enquanto encontram-se apenadas. Segundo o estudo, somente 10,58\% das pessoas que encontram-se apenadas no sistema prisional brasileiro encontram-se inseridas em algum tipo de atividade educacional (INFOPEN, 2017, p. 56). 


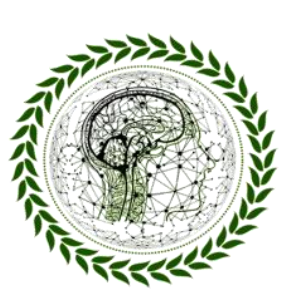

PhD Seientific Review

ISSN 2676 - 1444

As atividades educacionais englobam o ensino escolar propriamente dito e atividades complementares. Desse modo, as atividades de ensino escolar abrangem os cursos de alfabetização, ensino fundamental, médio e ensino superior, além de cursos técnicos de formação inicial, continuada e cursos profissionalizantes. As atividades complementares, por sua vez, compreendem os projetos de remição de pena pela leitura, estudo e esporte e pela participação em programas de cultura e lazer.

Ainda de acordo com o Levantamento Nacional de Informações Previdenciárias de 2017, o percentual de 10,58\% da população prisional inserido em atividades educacionais é dividido da seguinte forma 69.293 pessoas envolvidas no ensino regular, o que corresponde a 9,6\% e 7.520 pessoas envolvidas em atividades complementares, o que corresponde a 1,04\%. Ou seja, de 726.712 pessoas em situação de privação de liberdade, apenas 76.813 estavam inseridas em atividades educacionais em 2017 (INFOPEN, 2017, p. 59).

Dados mais recentes divulgados em 2020 pelo Departamento Nacional de Informações, referentes ao período julho a dezembro de 2019, indicam que o acesso à educação no sistema prisional brasileiro cresceu, mas ainda é muito baixo.

De acordo com o relatório $16.53 \%$ da população prisional está envolvida em atividades educacionais, o que totaliza 123.657 pessoas, uma vez que no período a população prisional era de 748.009 apenados e presos provisórios do sexo feminino e masculino, abrigados nos presídios estaduais e federais do país, excetuando do cômputo as pessoas em privação ode liberdade em sedes de polícias judiciárias, batalhões de polícia e bombeiros militares (INFOPEN, 2019, p. 4).

O mencionado relatório detalha que entre julho a dezembro de 2019 dentre as

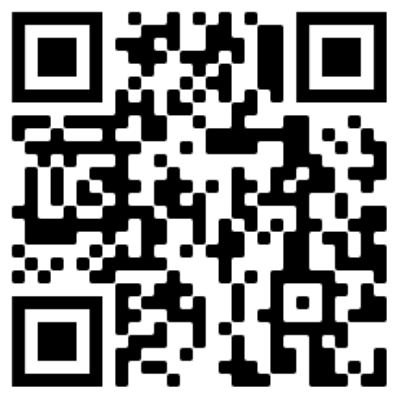

http://www.revistaphd.periodikos.com.br DOI: http://dx.doi.org/10.53497/phdsr2n1-004

V. 02, No 01, janeiro de 2022

Todos os direitos reservados (C) 


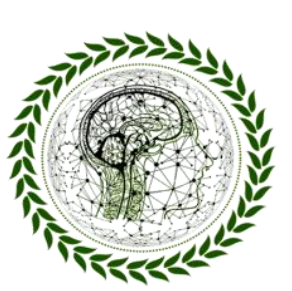

PhD Seientific Review

ISSN 2676 - 1444

pessoas em privação de liberdade envolvidas em atividades educacionais, 14.790 $(1,98 \%)$ estavam frequentando curso de alfabetização, 40.386 (5,40\%) cursavam o ensino fundamental, 19.077 (2,55\%) frequentavam o ensino médio, 796 (0,11\%) estavam cursando ensino superior, 17.416 (2,33\%) participavam de atividades complementares, $3.979(0,53 \%)$ eram alunas de cursos profissionalizantes, 27.208 (3,64\%) realizavam a remição pelo estudo e esporte (INFOPEN, 2019, p. 4).

O último Levantamento Nacional de Informações Penitenciárias, divulgado em dezembro de 2020 manteve a tendência de crescimento do acesso à educação no sistema prisional, contudo, os números continuam modestos.

O relatório revela que entre julho a dezembro de 2020, 165.127 pessoas dentre as 667.541 que se encontravam em privação de liberdade estavam envolvidas em atividades educacionais, representando $24,74 \%$ da população do sistema prisional. A participação em atividades educacionais se dividia da seguinte forma, entre os seguimentos: 12.624 (1,89\%) estavam em fase de alfabetização, 31.491 (4,72\%) frequentavam o ensino fundamental, 16.091 (2,41\%) cursavam o ensino médio, 770 $(0,12 \%)$ estavam matriculadas no ensino superior, $61.834(9,26 \%)$ integravam programas de atividades complementares, $2.303(0,34 \%)$ frequentavam cursos profissionalizantes, $40.041(6,00 \%)$ participavam de atividades de remição pelo estudo e esporte (INFOPEN, 2020, p. 5).

Desse modo, os dados apresentados indicam que há a necessidade de incentivo, ampliação do acesso e maior aporte de investimentos na educação prisional, de modo a tentar corrigir os prejuízos que o abandono escolar ou a falta de acesso à educação causou a essas pessoas em situação privação de liberdade. Nesse sentido, Leandra Silva afirma:

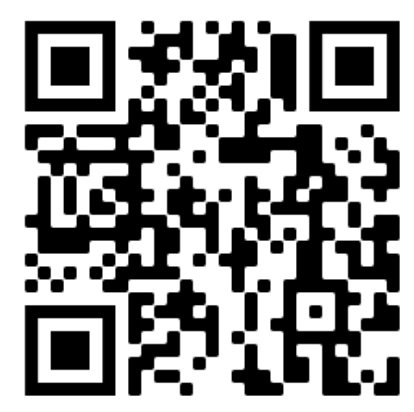

http://www.revistaphd.periodikos.com.br DOI: http://dx.doi.org/10.53497/phdsr2n1-004 V. 02, $\mathrm{N}^{\mathrm{o}}$ 01, janeiro de 2022 Todos os direitos reservados (C) 


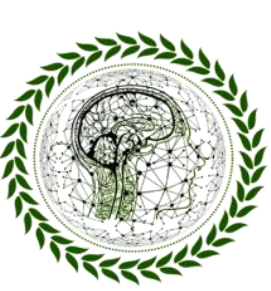

PhD Seientific Review

ISSN 2676 - 0444

\begin{abstract}
A educação escolar é uma realidade em quase todos os estabelecimentos Penitenciários espalhados pelo país, porém, enfrenta sérios problemas relacionados à falta de estrutura física e financeira, além da ausência de apoio do Poder Público na formulação de políticas públicas específicas e dos administradores desses estabelecimentos que priorizam a segurança, a disciplina e a vigilância. (SILVA, 2013, p. 179).
\end{abstract}

Ademais, além do incentivo financeiro e dos benefícios conferidos pela legislação aos apenados que se dedicam a atividades educacionais, é necessário que além de oferta de vagas também se propicie a conscientização dos benefícios que a educação irá propiciá-los para além do cárcere, na medida em que é instrumento de emancipação política, social e econômica.

\title{
RESULTADOS E CONSIDERAÇÕES FINAIS:
}

A análise dos aspectos relacionados ao direito das pessoas em privação de liberdade à educação no Brasil permite a observação de que este é um direito ainda pendente de concretização no âmbito de nosso sistema prisional. A porcentagem de presos envolvidos em atividades educacionais não ultrapassou 25\%, conforme aponta o mais recente e já citado Levantamento Nacional de Informações Penitenciárias, referente a dezembro de 2020.

Tendo em vista a importância da educação para formação de indivíduos críticos e conscientes, bem como considerando seu papel na redução das desigualdades sociais e no acesso a oportunidades que garantam aos indivíduos uma existência digna, é necessária uma ampliação do seu alcance no âmbito do sistema prisional.

Desse modo, compreende-se que a educação não é um antídoto com o poder

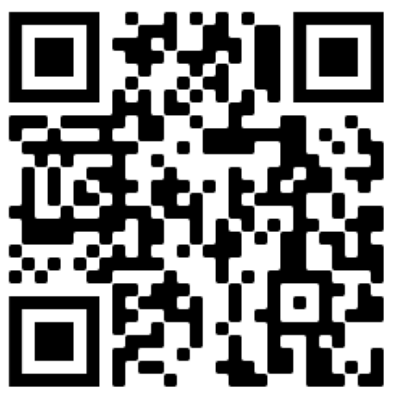

http://www.revistaphd.periodikos.com.br DOI: http://dx.doi.org/10.53497/phdsr2n1-004

V. 02, $\mathrm{N}^{\mathrm{o}}$ 01, janeiro de 2022

Todos os direitos reservados $($ ) 


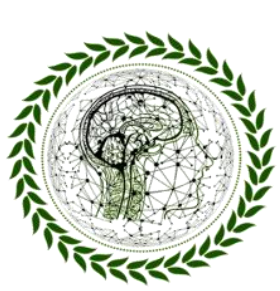

PhD Seientific Review

ISSN 2676 - 0444

de sanar instantaneamente complexa e multifatorial temática dos malefícios causados pela segregação social e a ausência de perspectivas do apenado posto em liberdade. Contudo, tendo em vista a situação de vulnerabilidade social e o estigma enfrentados por essa parcela da população ao retornarem ao convívio social, a educação é uma ferramenta indispensável para diminuição desses efeitos, de modo a viabilizar a socialização e evitar a reincidência e a marginalização social.

\section{REFERÊNCIAS BIBLIOGÁFICAS}

BARATTA, Alessandro. Ressocialização ou controle social: uma abordagem crítica da "reintegração social" do sentenciado. Alemanha. 2007. Disponível em http://www.egov.ufsc.br/portal/sites/default/files/anexos/13248-13249-1-PB.pdf. Acesso em: 22 set. 2021.

BRANDÃO, Carlos Rodrigues. O que é educação. Brasiliense, 2017.

BRASIL. Conselho Nacional de Justiça (CNJ). Regras de Mandela: Regras Mínimas Das Nações Unidas Para o Tratamento de Presos Brasília: CNJ; 2016.

BRASIL. Conselho Nacional de Justiça. Resolução No 391 de 10 de maio de 2021. Disponível em <https://atos.cnj.jus.br/atos/detalhar/3918> . Acesso em 19 de maio de 2021.

BRASIL. Constituição da República Federativa do Brasil de 1988. Diário Oficial da União 5 out. 1988; Disponível em: <http://www.planalto.gov.br/ccivil_03/constituicao/constituicaocompilado.htm>. Acesso em: 22 set. 2021.

BRASIL. Lei 7.210. Lei de Execução Penal. Brasília, DF: MJ, 1984. Disponível em: <http://www.planalto.gov.br/ccivil_03/leis/17210.htm>. Acesso em: 22 set. 2021.

BRASIL. Departamento Penitenciário Nacional. Ministério da Justiça. Levantamento

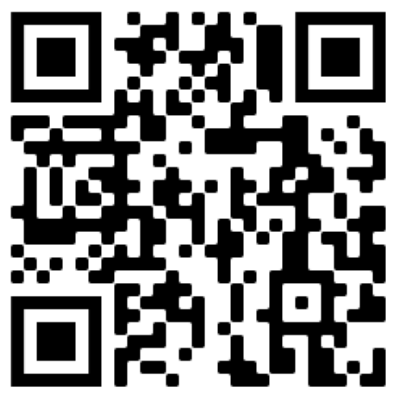

http://www.revistaphd.periodikos.com.br DOI: http://dx.doi.org/10.53497/phdsr2n1-004 V. 02, No 01, janeiro de 2022 Todos os direitos reservados $($ ) 


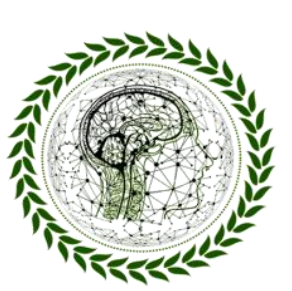

PhD Seientific Review

ISSN 2676 - 0444

Nacional de Informações Penitenciárias - INFOPEN - Junho de 2017. Disponível em: <http://antigo.depen.gov.br/DEPEN/depen/sisdepen/infopen>. Acesso em: 23 set. 2021.

BRASIL. Departamento Penitenciário Nacional. Ministério da Justiça. Levantamento Nacional de Informações Penitenciárias - INFOPEN - Dezembro de 2019. Disponível em: <http://antigo.depen.gov.br/DEPEN/depen/sisdepen/infopen> Acesso em: 23 set. 2021.

BRASIL. Departamento Penitenciário Nacional. Ministério da Justiça. Levantamento Nacional de Informações Penitenciárias - INFOPEN - Dezembro de 2020. Disponível em: < https://www.gov.br/depen/pt-br/sisdepen> Acesso em: 23 set. 2021.

BITENCOURT, Cezar Roberto. Falência da Pena de Prisão: Causas e Alternativas. 4. ed. São Paulo: Saraiva, 2011.

FOUCAULT, Michel .Microfísica do Poder. Tradução Roberto Machado. $24^{\mathrm{a}}$ edição. Rio de Janeiro: Editora Graal, 1979.

FOUCAULT, Michel. Vigiar e Punir: O Nascimento da Prisão. Tradução Raquel Ramalhete 35a edição. Petrópolis: Editora Vozes, 2008.

GRACIANO, Mariângela; SCHILLING, Flávia. A educação na prisão: hesitações, limites e possibilidades. Estudos de Sociologia, v. 13, n. 25, 2008

ROIG, Rodrigo Duque Estrada. Execução penal: Teoria Crítica. 5. ed. atual. São Paulo: Thomson Reuters Brasil, 2021. ISBN 978-65-5614-701-7.

RODRIGUES, Anabela Miranda. Reinserção Social: Uma Definição do Conceito. In: Revista do Direito Penal e Criminologia, Vol 34, Rio de Janeiro: Forense, junho/dezembro, 1982.

ROXIN, Claus, Problemas Fundamentais de Direito Penal. $1^{a}$ Ed. São Paulo: Veja, 1986.

SILVA, Leandra Salustiana Oliveira da; DE ARAÚJO, Elson Luiz. A educação escolar

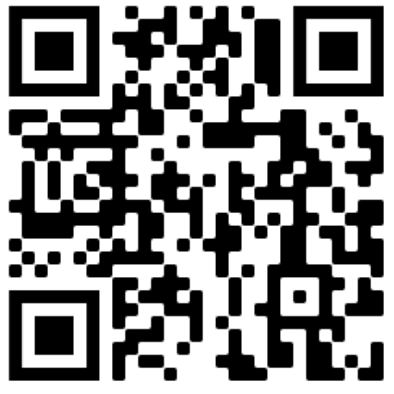

http://www.revistaphd.periodikos.com.br DOI: http://dx.doi.org/10.53497/phdsr2n1-004

V. 02, No 01, janeiro de 2022 Todos os direitos reservados $($ ) 


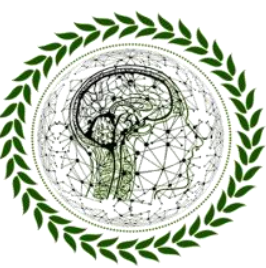

PhI Scientific Review

ISSN 2676 - 0444

nas prisões: um olhar a partir dos direitos humanos. Revista Eletrônica de Educação, v. 7, n. 1, 2013. 